\title{
Contribuições do behaviorismo radical para a psicologia e desenvolvimento das concepções de metodologia e método científico
}

\section{Contributions of radical behaviorism to psychology and development of scientific methodology and method of science conceptions}

\author{
Eduardo José de Souza, Olga Mitsue Kubo
}

[1] Universidade Federal de Santa Catarina (UFSC), Brasil | Título abreviado: Behaviorismo radical: Contribuições para psicologia e ciência | Endereço para correspondência: Olga Mitsue Kubo. Rua das Acácias, 464. CEP: 88040-560. Florianópolis, SC. | E-mail: cmte.edu@gmail.com

\begin{abstract}
Resenha da obra: Batista, T. M. (2007). O legado filosófico de B. F. Skinner: As influências filosóficas iniciais e a epistemologia da análise experimental do comportamento (Dissertação de mestrado não publicada). Universidade Federal de Santa Catarina, Florianópolis, SC.
\end{abstract}

"Diga-me o que controla teu comportamento e direi se tu és cientista!". A frase parece ser brincadeira, mas indica aspectos importantes a respeito da concepção de método científico e de sua função no processo de produzir conhecimento. Do desenvolvimento da concepção de método científico como controle de variáveis que influenciam na observação do fenômeno investigado até a concepção de método científico como controle das variáveis que influenciam todo o processo de conhecer, incluindo variáveis relacionadas ao comportamento do cientista, há contribuições de diversos autores com conhecimento produzido por diferentes formas de conhecer ao longo do tempo, principalmente da ciência e da filosofia.

Apresentar a obra de Thiagus Batista, um filósofo, tem como objetivo principal examinar parte dessas contribuições, especialmente aquelas advindas do behaviorismo radical. Busca-se, com isso, possibilitar ao leitor avaliar as contribuições dessa filosofia da ciência para a consolidação da psicologia como área de conhecimento científico e para o desenvolvimento da própria ciência como uma forma específica de conhecer fenômenos e processos. Por esse motivo, a leitura da obra é relevante para os analistas do comportamento - desde os iniciantes, como ajuda para caracterizar o behaviorismo radical e a análise do comportamento como uma contribuição localizada historicamente, até os mais experientes, responsáveis por formar novos profissionais capazes de produzir conhecimento científico, motivo pelo qual precisam avaliar o desenvolvimento das concepções de metodologia científica e método da ciência ao longo do tempo.

Uma parte da obra que pode ser de especial interesse aos analistas do comportamento, principalmente para as novas gerações, é o Capítulo 1 . Nele, há a explicitação das principais influências nas proposições de B. F. Skinner, com destaque para a figura de Bertrand Russell, autor que apresentou a filosofia do behaviorismo a B. F. Skinner. Vale notar também a influência do físico Ernest Mach, que concebia a explicação científica como descrição de 
eventos e identificação de relações funcionais entre eles. Destaca-se ainda Charles Darwin, que propôs o processo de seleção natural para explicar a evolução das espécies. Apesar de as principais influências serem apresentadas nesse capítulo, há outras que não foram examinadas pelo autor e, se o leitor desejar conhecê-las, pode conferir a obra de Michael (2004). Um recurso que facilita bastante a compreensão desse capítulo é a clara e gradual indicação da influência de cada autor nos pressupostos do behaviorismo radical. Dessa forma, a leitura do capítulo possibilita localizar a proposição do behaviorismo radical em um contexto social e histórico, o que aumenta a chance de considerá-lo mais como uma contribuição para a psicologia e menos como uma "abordagem" ou "escola" a ser adotada e defendida de acordo com preferências pessoais ou profissionais.

Após apresentar as principais influências de outros pensadores na proposição do behaviorismo radical, Thiagus Batista faz um exame das influências dessa filosofia na psicologia. O autor explicita como o behaviorismo radical contribuiu para que a psicologia superasse as noções de causa e efeito e de determinismo absoluto dos fenômenos, passando a considerar as múltiplas relações funcionais que alteram a probabilidade de ocorrência do comportamento, assim como ocorre na explicação de fenômenos estudados pela física, considerada como área de vanguarda na descoberta e proposição de relações probabilísticas na determinação de fenômenos e processos. O autor também examina como foi possível aproveitar as descobertas do processo de seleção natural, inicialmente utilizado para entender a evolução das espécies na biologia, para explicar a seleção e a manutenção de comportamentos dos organismos. Conhecer essas influências é importante, pois possibilita compreender, por exemplo, o que fundamenta procedimentos comumente utilizados por analistas do comportamento, como a utilização de animais como sujeitos para investigar processos comportamentais e a realização de experimentos em ambientes controlados. Fica mais fácil compreender o uso desses tipos de procedimentos quando se sabe que o behaviorismo radical, como filosofia que sustenta a análise do comportamento, assume que há continuidade entre as espécies e que o comportamento tanto de animais como de humanos é selecionado por suas consequências. Essa asserção torna possível estudar processos comportamentais com a utilização de animais como sujeitos em ambientes controlados que minimizam a influência de variáveis intervenientes, para tornar possível a investigação de relações funcionais específicas entre a atividade do organismo e aspectos do meio. De maneira geral, a leitura do Capítulo 1 permite ao leitor perceber como o behaviorismo radical contribuiu para que a psicologia se orientasse por princípios que fossem coerentes com as descobertas de outras áreas do conhecimento científico, como a física e a biologia, o que também favoreceu a consolidação da psicologia como área de conhecimento científico, distanciando-a de uma área metafísica do conhecimento.

Outra contribuição do behaviorismo radical para a consolidação da psicologia como uma área de conhecimento científico foi a definição mais precisa de seu objeto de estudo. De acordo com Botomé e Kubo (2002), uma área de conhecimento é definida pela organização do conhecimento produzido a respeito de determinado objeto de estudo. Em outras palavras, a psicologia como área de conhecimento, para ser considerada como tal, requer um objeto de estudo claramente delimitado. O Capítulo 2é dedicado ao exame de considerar o "comportamento" como objeto de estudo da psicologia. Thiagus Batista analisa como a psicologia se sustentou na definição do comportamento como objeto de estudo. Apesar de não se deter no exame da própria noção de comportamento, o autor argumenta como foi possível que a psicologia passasse a investigar o comportamento com alto grau de controle e verificação por meio da experimentação - o que, por sua vez, possibilitou até mesmo a previsão e o controle do comportamento, inclusive em situações práticas ou de aplicação do conhecimento científico.

As influências iniciais nas proposições de B. F. Skinner possibilitam avaliar como o behaviorismo radical, em sua gênese, beneficiou-se das descobertas de outras áreas do conhecimento científico, como a física e a biologia. No entanto, a leitura da obra possibilita também que seja realizada uma avaliação inversa: em que aspectos a forma de conhecer científica pode se beneficiar das proposições do behaviorismo radical? Ao longo de toda a sua obra, Thiagus Batista apresenta um exame das contribuições do behaviorismo radical para a ciência, mas é na primeira parte do Capítulo 3que tal exame é mais 
explícito. Nessa parte, o autor analisa a concepção de metodologia científica para o behaviorismo radical. A partir de considerações feitas pelo próprio Skinner, o autor explicita a concepção advinda do behaviorismo radical de que metodologia científica consiste na investigação do comportamento do cientista ao produzir conhecimento científico. Tal ponto de vista é ilustrado pelo autor por meio de citações de trechos nos quais Skinner (1956/1975) apresenta princípios metodológicos identificados a partir de sua história pessoal, ou seja, a partir do exame de seu próprio comportamento como cientista. Ainda nessa parte da obra, discutem-se as implicações para o ensino da ciência, as quais muitas vezes se resumem ao ensino de técnicas e procedimentos utilizados por outros cientistas, considerados como regras a serem seguidas. Essa discussão pode ser de especial interesse para profissionais que necessitam capacitar pessoas a produzir conhecimento científico, pois explicita que procedimentos e técnicas não são regras a serem seguidas para observar a ocorrência do fenômeno estudado, mas sim formas de controlar as variáveis que interferem no processo de conhecer. A partir desse exame, o autor explicita ainda outro importante conceito, o de método da ciência. Este, de acordo com Botomé (1997), refere-se ao controle das variáveis que interferem no processo de conhecer como um todo, incluindo variáveis relacionadas ao comportamento do próprio cientista, e não apenas ao controle das variáveis que interferem na observação do objeto de estudo, conforme Skinner $(1956 / 1975)$ salienta em seu relato. Talvez uma das obras em que as concepções de metodologia científica e método da ciência, tal como são examinadas na dissertação de Thiagus Batista, fiquem mais evidentes é o clássico Táticas da Pesquisa Científica: Avaliação dos Dados Experimentais na Psicologia, de Murray Sidman (1960/1976), cuja leitura pode ser o próximo estágio para o leitor interessado na concepção de metodologia científica como análise do comportamento do cientista ao produzir conhecimento e de método da ciência como controle das variáveis que interferem no processo de conhecer.

A segunda parte do Capítulo 3 complementa a discussão acerca do método da ciência como correspondendo ao controle das variáveis que interferem no processo de conhecer como um todo, pois nesta parte é analisada a função da experimenta- ção na psicologia e na ciência em geral. $\mathrm{O}$ autor salienta que o método experimental se refere apenas ao controle das variáveis que interferem na observação do fenômeno a ser investigado, de modo que não é possível confundir (nem resumir) a utilização de procedimentos experimentais com o fazer científico, da mesma forma como não é possível considerar um estudo como sendo científico apenas pela utilização de certos procedimentos, como os estatísticos, por exemplo. Este capítulo esclarece a concepção errônea e comumente difundida no meio acadêmico de que o status científico de uma pesquisa se deve apenas aos procedimentos e instrumentos empregados, o que representa um equívoco mesmo quando tais procedimentos são experimentais. $\mathrm{O}$ exame realizado pelo autor merece a atenção de analistas do comportamento, pois grande parte do conhecimento produzido sob o rótulo de análise do comportamento resulta de experimentação e muitas vezes a função da experimentação em um processo de produção de conhecimento não fica clara, principalmente para as gerações mais jovens de analistas do comportamento, passíveis de considerar como único aspecto definidor da análise do comportamento a utilização de experimentos na produção de conhecimento.

Na terceira e última parte do Capítulo 3, o autor relaciona a metodologia científica na perspectiva do behaviorismo radical com a perspectiva apresentada pelo filósofo Paul Feyerabend. É provável que esta parte seja a de menor interesse para analistas do comportamento em geral. No entanto, é relevante para os leitores que quiserem se aperfeiçoar no estudo da metodologia científica, pois a concepção de metodologia da pesquisa científica decorrente dos pressupostos do behaviorismo radical provavelmente é uma de suas contribuições mais importantes para a ciência. A concepção de método da ciência caracterizado pelo controle realizado pelo cientista das variáveis que interferem no processo de conhecer implica necessariamente uma mudança na concepção do que é metodologia científica, a qual passa a ser considerada como investigação do comportamento do cientista ao produzir conhecimento científico. Definida dessa forma, a metodologia científica, como conjunto sistematizado de conhecimento, muito provavelmente se beneficiará do conhecimento produzido pela análise do com- 
portamento, pois esse tipo de conhecimento consiste exatamente na investigação do comportamento, entendido como interação entre aquilo que os organismos fazem e os aspectos do meio. Esse é um indício de que talvez existam muito mais aspectos em comum entre epistemologia, metodologia científica e análise do comportamento do que se imagina.

O Capítulo 4 complementa o exame, já realizado com minúcia pelo autor no Capítulo 2, das decorrências para a psicologia de considerar o comportamento como o seu objeto de estudo. No Capítulo 4, Thiagus Batista demonstra a impossibilidade de uma área de conhecimento científico constituir-se pela investigação de um objeto explicado a partir de inferências, as quais recorrem a entidades internas ou mentais como causas do comportamento, postura típica da psicologia tradicional. É nessa parte da obra que as contribuições do behaviorismo radical para a psicologia ficam mais evidentes a partir do exame das explicações mentalistas do comportamento.

No Capítulo 5, Thiagus Batista dedica-se à discussão acerca da explicação científica, de modo que as noções de causalidade e de análise funcional são examinadas com mais detalhes do que no Capítulo 1, no qual apresentou-se as influências do físico Ernest Mach na proposição dos princípios do behaviorismo radical de B. F. Skinner. Mostrase com clareza que a explicação científica deixa de consistir na descoberta das causas dos fenômenos e passa a ser concebida como descoberta de relações funcionais entre eventos que alteram a sua probabilidade de ocorrência. A leitura permite ao leitor notar as decorrências para a psicologia de se conceber a explicação científica como identificação de múltiplas relações funcionais, o que evidencia a relevância de identificar e descrever as variáveis ambientais relacionadas àquilo que os organismos fazem, em detrimento de explicações baseadas em entidades internas como mente, sentimentos e pensamentos como causadores do comportamento.

Ainda com relação à explicação científica, Thiagus Batista examina o aspecto da veracidade de tais explicações. No caso do behaviorismo radical, o autor demonstra que um critério crucial de veracidade de uma explicação é o grau de eficiência obtido ao relacioná-la com aspectos do ambiente. A leitura do capítulo é importante, pois a questão da veracidade de uma explicação pode ser relacionada com a necessidade de o analista do comportamento avaliar constantemente a validade do conhecimento que produz. A última parte do capítulo sobre explicação científica questiona ainda a adequação da previsão e do controle como objetivos da ciência. Se a veracidade de uma explicação científica é sustentada pela efetividade que tal explicação proporciona ao se relacionar com o ambiente, então a previsão e o controle de eventos seriam decorrências do critério de veracidade proposto pelo behaviorismo radical. Diante de tal constatação, Thiagus Batista apresenta argumentos contrários à proposta de validação de uma explicação por meio de previsão e controle dos fenômenos, o que sem dúvida é relevante para o debate acerca dos objetivos da ciência. Enfim, o autor conclui que de fato o behaviorismo radical possui coerência interna e que certamente pode contribuir ainda mais para a compreensão do que é, constitui ou define a forma de conhecer científica. Um indício de que ainda possa haver contribuições a explorar é a permanência de certos questionamentos. Afinal, se prever e controlar são objetivos da ciência, fazemos isso para quê? Para quem? O que e em que grau deve controlar e manter o comportamento do cientista? Prestígio, financiamento, benefícios pessoais ou sociais? São questões cruciais a serem respondidas, principalmente após ter sido explicitada a característica nuclear do método da ciência: o controle das variáveis que interferem no processo de produzir conhecimento científico, inclusive as variáveis relacionadas ao comportamento do próprio cientista. Sendo assim, a dissertação de Thiagus Batista esclarece a relevância da discussão acerca dos objetivos da ciência, com destaque para o fato de que prever e controlar provavelmente não são fins em si mesmos, mas sim meios para se atingir algo de valor para a sociedade.

Em síntese, a obra de Thiagus Batista é relevante para analistas do comportamento, pois explicita as contribuições do behaviorismo radical para a consolidação da psicologia como área de conhecimento científico, principalmente ao definir um objeto de estudo e formas de estudá-lo coerentes com essa forma de conhecer. Além disso, a discussão acerca das contribuições da concepção de método da ciência e metodologia científica derivada do behaviorismo radical é de considerável relevância ao se considerar a incompreensão acerca do que se entende por 
metodologia científica, até mesmo por aqueles responsáveis por capacitar outras pessoas a produzirem conhecimento científico. A obra também suscita reflexões a respeito de aspectos que parecem ser pontos pacíficos, como o objetivo da ciência, proposto por Skinner (1953/1970), que seria o de controlar e prever fenômenos, mas que podem ser questionados da perspectiva de sua finalidade. Um último aspecto positivo da obra é que ela pode ser obtida integralmente por meio do site da biblioteca virtual da universidade em que a dissertação foi defendida, acessando o seguinte endereço eletrônico: http:// www.tede.ufsc.br/teses/PFIL0076-D.pdf. Da mesma forma que a ciência se beneficiou das contribuições do behaviorismo radical, certamente o leitor irá se beneficiar da leitura desta obra.

\section{Referências}

Botomé, S. P. (1997). Processos comportamentais básicos em metodologia de pesquisa: $\mathrm{Da}$ delimitação do problema à coleta de dados. Chronos - Revista da Universidade de Caxias do Sul, 30(1), 70-102.

Botomé, S. P., \& Kubo, O. M. (2002). Responsabilidade social dos programas de pós-graduação. Interação em Psicologia, 6(1), 81-110.

Michael, J. L. (2004). Historical antecedents of behavior analysis. Em J. L. Michael (Org.), Concepts \& principles of behavior analysis (pp.93-104). Kalamazoo: Association for Behavior Analysis International.

Sidman, M. (1976). Táticas da pesquisa científica: Avaliação dos dados experimentais na Psicologia (M. E. Paiva, Trad.). São Paulo: Editora Brasiliense. (Trabalho original publicado em 1960)

Skinner, B. F. (1970). Ciência e comportamento humano (2a ed.; J. C. Todorov \& R. Azzi, Trads.). Brasília: Editora UnB. (Trabalho original publicado em 1953)

Skinner, B. F. (1975). Un caso dentro del método científico. Em B. F. Skinner (Org.), Registro Acumulativo (pp. 112-137). Barcelona: Editorial Fontanella. (Trabalho original publicado em 1956)

\section{Informações do artigo}

\section{História do artigo}

Data de submissão em: 20/06/2011

Primeira decisão editorial em: 15/08/2011

Aceito para publicação em: 31/10/2011 